\title{
PHARMACEUTICAL SCIENCES
}

\section{UPGRADE AND USING WEB 2.0 SERVICE IN STUDY PROCESS OF PHARMACEUTICAL STUDENTS}

\author{
Mandzii Taras ${ }^{1}$ \\ Kucheriavyi Yurii ${ }^{2}$
}

DOI: https://doi.org/10.30525/978-9934-571-89-3_85

To be in demand in the labor market, you need to navigate and understand many novelties. It's impossible to imagine a person or a future specialist who would not use Skype, a navigator or search systems (services). The motives for personal teacher modernization (for specialists) should be the desire to learn new methods of learning and to increase their knowledge, develop for themselves and keep up with the IT staff. This is especially true for teachers who teach students in higher medical institutions [1;2, p. 792].

The most common services: - Google Drive provides 15 GB (including e-mail storage) space on your disk; - Dropbox is 2 GB (can be increased up to 16 GB free of charge); - Yandex Disk provides $10 \mathrm{~GB}$ free of charge, which can be increased up to 20 GB (also, temporarily, you can use more disk space); - WEB 2.0 is a method of system designing; - Mega is providing free 50 GB of disk space; - Office 365 is a cloud service, which provides a collaborative work of the companies or organizations, with $5 \mathrm{~GB}$ of disk space for free on OneDrive.

Recently, more and more services have been created on the Internet, which are built on the WEB 2.0 technology. WEB 2.0 is a method of systems designing. Main idea of WEB 2.0 is getting better with the taking into account network interactions, and the amount of users. The using of social services in study process can contribute to the development of such important skills as critical thinking, collective creativity, and team interaction. Modern Web 2.0 social services open up unlimited horizons for application in educational, professional, personal and social activities, namely: - use of open, free and free digital resources; - independent creation of network educational content; providing and receiving distance consultations; - creation and participation in groups (communities) for preferences; - development of new concepts of the information environment; - gaining new knowledge and developing new skills; - collective creativity and collaborative interaction; - participation in the activities of the network community [3; 4].

To our mind, it is necessary to apply also electronic educational resources from the information support of vocational guidance work of teachers of natural and

\footnotetext{
${ }_{1}^{1}$ Ivano-Frankivsk National Medical University, Ukraine

${ }^{2}$ Zaporizhzhia State Medical University, Ukraine
} 
mathematical specialties to obtain professional education and the subsequent selfsufficient work in market conditions, along with traditional methods of vocational guidance.

Increasingly, Internet users prefer small amount of information in different formats and from different sources (blogs, YouTube, Flickr, etc.) instead of reading large volumes of documents. Now due to social services everyone can not only gain access to digital collections, but also participate in the formation of their own network content or join in its cooperative development.

Last time many services have appeared supporting collective work on a joint project. The known example is Google Drive. Taking into account the wide range of functionality, for example, such services as Diigo, YouTube, Google Drive, FreeMind, Blogger, Twitter, FaceBook, LinkedIn, iGoogle, Webinar can be used in career-oriented activities. Diigo is a personal information management system. It is a service storage of the various sites links and links to pieces of text on the site pages. The user can save private or public (they will see everyone) bookmarks. A bookmark is a record that consists of a link to a particular site or a text piece, its title and a brief description. Also, the service allows you to create groups and invite users to them.

The bookmarks of sites on specific topics can be posted in groups. The service can be used for collective work of students with materials for professional orientation: to highlight the main thing, to make bookmarks, and so on. Such services as http://www.bobrdobr.ru - BobrDobr; http://delicious.com/ - Delicious; http://memori.ru/ - Memori also perform the similar functions.

YouTube is a web hosting service. Users can add, view and comment on videos. The service also allows users to recommend videos to others. According to Alexa.com, YouTube is ranked third in number by number of visitors. You can use it to post, search, comment, and distribute video material from your professional orientation.

Google Drive allows users to create, save, edit directly on-line, even without installed office software on the user's computer, view documents on the network and share them with other users. The service supports collective work with documents. Using this service you can create: text documents, tables, presentations, forms (a form with a list of questions and answers - tests), drawings (diagrams, graphs, etc.). With the help of this service, a career advisor can make surveys and tests, organize a collective discussion of a certain material, and so on.

FreeMind or knowledge maps (cognitive maps, mental maps) are schemes in presented with various ideas, tasks, and abstracts are presented, connected with each other and combined by a common idea. The user can structure information in the form of diagrams and provide it to students using this service.

Blogger is a network diary service. Usually blogs are public and involve thirdparty readers who can enter into controversy with the author. But there are private blogs. The content of such blogs can only be seen by the author. The main content of blogs are posts that are regularly added and contain text, images or multimedia. For blogs, short records are sorted in reverse order (last record above). The links to 
documents, video materials, career guidance sites and other materials can be placed on the blog.

Twitter is the network of microblogging has become a further development of the idea of blogging. You can send messages to the Twitter network using the web interface, client applications or SMS. Thanks to the ease of sending messages and the speed of news distribution, The Twitter is called a new kind of media due to easy massage sending and fast news flash. Even some periodicals have their own representation on this network.

LinkedIn is a social network for finding and establishing business contacts. Contacts can be requested both from the site and from the outside, but LinkedIn requires prior known with the contacts. In the case where the user does not have a direct relation with the contact, he can be represented through another contact (friend of a friend). LinkedIn users can use a contact list for a variety of purposes: to be represented through existing contacts and to expand relations; search for companies, people, interest groups; publish professional resume and search job; recommend and be recommended; publish vacancies; create interest groups.

iGoogle is a service that allows you to create a personalized start page or a personalized Internet portal. The page is organized in tables. Each table contains custom modules. For example, search using Google, RSS streams, weather forecasts in the selected region, bookmarking module, etc. [3].

Webinar (http://webinar.ipo.kpi.ua/) is a platform for conducting web-seminars (webinars). The service provides the opportunity for the leader (moderator, trainer, consultant, teacher) to transfer information, and participants allows receive information and learn with the help of a virtual class that has the ability to hear and see each other wherever you are. Especially important features: participants show presentation, draw on a virtual whiteboard, doing active survey. The members can ask questions in the online chat window for better interactivity. It also can be used: http://wiziq.com - WizIQ, www.comdi.com - Comdi, www.dimdim.com - Dimdim.

Now we are witnessing the rapid development of social media. The question that has to be answered is how to assess the impact of mass services on the goals set using social services to build a personal learning environment? There is a need for collecting and processing statistical information about participants' activities. Statistical reports will help assess the impact of social media on achieving goals. The combined data of WEB analysis and social activity allows you to get a general idea of the content and community activity about it [5, p. 684].

Recently, tools for collecting statistic data from the most famous search engines such as Yandex.Metrics and Google Analytics are very popular. Google Analytics is a free service for keeping detailed statistics about visits to websites from Google. The service allows you to evaluate the traffic of the website and the effectiveness of various marketing activities. It also provides advanced data analysis capabilities, including displaying them in convenient graphs. The service works using HTTPS. Analyst is used by about $49.95 \%$ of 1,000,000 leading websites (according to Alexa.com). The free version is limited to 10 million pageviews per month. Users with an active Google AdWords account have the ability to track unlimited number 
of pageviews. Currently, Google Analytics has the ability to build 80 types of reports that can be customized. The examples are daily visits (number of visitors per day, week, month, etc.), pageviews, average visit duration, bounce rate (percentage of views for which the page was viewed only), percentage of new visits, types of traffic (source of site referrals), popular search queries with which the user came to the site, the time of staying on the site by country, display of statistics on visits to the world map, activity in social networks (how many visitors of the site shared information in social networks) achieved the target (indicated conversions to the page marked binding site administrator to view it) and so on.

\section{References:}

1. Morze, N. V., \& Glazunova, O. G. (2008). Models of effective use of information communication and distance learning technologies at higher educational institutions. Information technology and learning tools, 2(6). Retrieved from: http://www.ime.eduua.net/em6/content/ 08mnvshi.htm.

2. Soldatkin V. I. (2003) Prepodavanie v seti Internet [Internet teaching]. Moscow: Vysshaya shkola. (in Russian)

3. WEB 2.0 social service activities in vocational teaching staff (2013). Electronic resources. Retrieved October 27, 2013 from: http://dist.org.ua/mod/page/view.php?id=258.

4. Typology Web 2.0. (2012). Electronic resources. Retrieved April 19, 2012 from http://www.eduwiki.uran.net.ua/wiki/index.php/ Typology_Web_2.0.

5. Stepanov A. N. (2006) Informatika [Informatics]. Saint Petersburg: Piter. (in Russian). 